\title{
Blubber fatty acid profiles indicate dietary resource partitioning between adult and juvenile southern elephant seals
}

\author{
China Newland ${ }^{1, *}$, Iain C. Field ${ }^{1,2}$, Peter D. Nichols ${ }^{3,4}$, Corey J. A. Bradshaw ${ }^{5,6}$, \\ Mark A. Hindell ${ }^{1,4}$ \\ ${ }^{1}$ Antarctic Wildlife Research Unit, School of Zoology, University of Tasmania, Private Bag 05, Hobart, Tasmania 7001, Australia \\ ${ }^{2}$ School for Environmental Research, Institute of Advanced Studies, Charles Darwin University, Darwin, \\ Northern Territory 0909, Australia \\ ${ }^{3}$ CSIRO Marine and Atmospheric Research, Food Futures Flagship, GPO Box 1538, Hobart, Tasmania 7000, Australia \\ ${ }^{4}$ Antarctic and Climate Ecosystems CRC, Private Bag 80, Hobart, Tasmania 7001, Australia \\ ${ }^{5}$ Research Institute for Climate Change and Sustainability, School of Earth and Environmental Sciences, \\ University of Adelaide, Adelaide, South Australia 5005, Australia \\ ${ }^{6}$ South Australian Research and Development Institute, PO Box 120, Henley Beach, South Australia 5022, Australia
}

\begin{abstract}
When resources are limited or patchy, a species may develop some degree of resource partitioning to reduce intra-specific competition. Development of intra-specific resource partitioning is more pronounced in species with clear phenotypic variation among individuals (e.g. age or sex). Southern elephant seals Mirounga leonina have pronounced sexual dimorphism and range widely in size and foraging range between juvenile and adult stages. However, hypothesized diet-based resource partitioning has been less clear due to difficulties in sampling diet while seals are away from breeding islands. We analysed fatty acids (FAs) from blubber of 122 juvenile seals and compared them to FA profiles from blubber of 52 adult females, and to FA profiles from 51 prey species (grouped as fish and squid) to examine evidence for diet-based resource partitioning in the seals. FA signature analysis revealed physiological and dietary differences between ages. Principle components of the 21 FAs from seal blubber and prey parts distinguished prey from seals, and clearly separated prey species into fish and squid classes. FA profiles from adult females differed to those from juveniles, with the former more 'squid-like' and the latter more 'fish-like'. Variation in FA profiles of seals was also apparent between sexes and during different seasons. Differences in diet between juveniles and adult females suggest resource partitioning occurs in response to large metabolic and physiological differences with age that limit juvenile dispersal and diving abilities. By consuming a different suite of prey species relative to adult females, juvenile southern elephant seals may reduce intra-specific competition.
\end{abstract}

KEY WORDS: Fatty acid signature analysis $\cdot$ Southern elephant seal $\cdot$ Diet $\cdot$ Resource partitioning

\section{INTRODUCTION}

Competition for resources is a primary driving force behind community structure, with both inter-specific and intra-specific competition defining a species' ecological niche (Bolnick et al. 2003). When resources are limited or patchy, many species demonstrate some degree of resource partitioning to reduce intra-specific competition through ontogenetic shifts in morphology, habitat use, or foraging behaviour between members of the population (Bolnick et al. 2003, Field et al. 2005a, Polis 1984). Intra-specific resource partitioning is more 
distinctive in individuals of different age and sex or life-history stage with obvious morphological differences (Polis 1984, Bolnick et al. 2003). Thus, intraspecific resource partitioning should be more pronounced in species with large phenotypic variation between age and sex classes.

The sexually size dimorphic southern elephant seal Mirounga leonina is the largest of all the pinnipeds and exhibits pronounced morphological and physiological differences with age (Field et al. 2005b). Adult body size of males (up to $4 \mathrm{t}$ ) is 5 to 10 times that of females $(0.5 \mathrm{t})$. This large body mass and an estimated population size of 757000 (McMahon et al. 2005) make this species a major consumer of marine resources in the Southern Ocean, of which squid, and perhaps to a lesser extent fish, make up the bulk of the diet (Green \& Burton 1993, Slip 1995, Hindell et al. 2003). These factors, combined with the unpredictable and patchy environment of the Southern Ocean in which they spend most of their lives, make southern elephant seals prime candidates for the evolution of mechanisms that reduce competition through intra-specific resource partitioning.

The decline in the southern elephant seal population at Macquarie Island over the last 3 decades has been linked to changes in resource availability, to which the juvenile seals (seals that have not reached sexual maturity, 1 to $4 \mathrm{yr}$ ) appear to be the most susceptible (Hindell 1991, Hindell et al. 1994, Laws 1994, McMahon et al. 2005). Some support for this is provided by the age-specific habitat use observed in this species, such that there is reduced overlap between the regions used by different age classes (Field et al. 2005a). Younger seals used a smaller total area and travelled shorter distances compared to older seals (Field et al. 2005a), suggesting they may exploit different resources compared to adults. However, attempts to test this hypothesis explicitly by quantifying age-specific diets based on stomach contents have been difficult. Slight differences in the squid components of the diet were identified between 1 yr olds and 2 and 3 yr olds (Field et al. 2007), but, because stomach contents reveal only the most recent meals, these results provide only weak support (Harvey \& Antonelis 1994, Fea \& Harcourt 1997).

Indirect methods are being used increasingly to quantify the diet of many marine species. Fatty acid (FA) signatures derived from the blubber of marine mammals have been used in conjunction with stomach contents and genetic analyses to provide more details on dietary composition and variation and to avoid the previous biases associated with stomach content analysis alone (Hooker et al. 2001, Bradshaw et al. 2003, Herman et al. 2005, Nordstrom et al. 2008). FAs are the main constituent of most lipids, and, unlike other components such as proteins that are readily broken down during digestion, FAs are released from ingested lipid molecules (e.g. triacylglycerols and phospholipids) during digestion, but are not subsequently degraded (Iverson et al. 2004). The FAs with carbon chain-lengths $\geq \mathrm{C} 14$ pass into the circulation intact and are generally assimilated by tissues. Not all FAs can be biosynthesized by animals, so it is possible to distinguish diet- versus non-diet-derived FAs (Volpe \& Vagelos 1973, Bremer \& Norum 1982, Wakil et al. 1983, Iverson et al. 2004). Once assimilated, FAs are either used for energy or are re-esterified, primarily to triacylglycerols, and stored in adipose tissue that assists in heat retention and energy storage (Iverson et al. 2004). Therefore, some metabolism of FAs may occur, and the composition of FAs in predator tissues does not exactly match that of their prey. Vertical stratification within blubber will also alter the FAs deposited in adipose tissue (Best et al. 2003), although in a predictable way with little modification (Volpe \& Vagelos 1973, Bremer \& Norum 1982, Wakil et al. 1983, Best et al. 2003, Iverson et al. 2004). Differential FA catabolism may also increase the uncertainty of diet interpretations (Wheatley et al. 2007).

Differences in the FA composition of the blubber of marine mammals, among individuals (Iverson et al. 1997), populations (Moller et al. 2000), or even species (Borobia et al. 1995), are therefore partially a function of the differences in the FA composition of their prey. However, the degree to which predator FAs are modified from those ingested is difficult to ascertain, because diets and metabolic requirements differ between and within species (Olsen \& Grahl-Nielsen 2003). To examine further how variation in FA composition is a true reflection of prey ingestion, quantitative FA signature analysis (QFASA) has been developed (Iverson et al. 2004). This method requires a series of complex and expensive feeding trials to calibrate the FA variation in prey species ingested with those eventually extracted from the predator (Iverson et al. 2004). Without ready access to feeding trials in any particular species, however, calibration is difficult.

Previous studies using FA signature analysis (FASA) to determine the diet of adult southern elephant seals have identified differences between foraging areas and seasons (Bradshaw et al. 2003) and relative to other predatory pinnipeds (Brown et al. 1999, Hindell et al. 2000). For example, Bradshaw et al. (2003) determined the relative proportions of squid and fish in the diet of adult females. Because blubber FAs contain a dietary signal representing many months, FASA is a powerful method for identifying the degree of dietary resource partitioning within age and sex classes of southern elephant seals. In the present paper, we quantify the FA composition of blubber from juvenile 
southern elephant seals from Macquarie Island to fill this gap in our understanding of the ontogeny of elephant seal foraging. We aimed to: (1) describe seasonal and sex- and age-related variation in the FA signature profiles of juvenile southern elephant seal blubber, (2) compare FA signature profiles from juveniles with those from adult females, (3) make inferences about dietary habits and the potential for dietary resource partitioning between juveniles and adults.

\section{MATERIALS AND METHODS}

All of the seals examined were marked as pups at the isthmus breeding colony on Macquarie Island, in the Pacific sector of the Southern Ocean $\left(54^{\circ} 35^{\prime} \mathrm{S}\right.$, $\left.158^{\circ} 55^{\prime} \mathrm{E}\right)$, as part of the mark-recapture study from 1993 to 2002 (McMahon et al. 2003). We sampled a total of 122 male (65) and female (57) juvenile southern elephant seals Mirounga leonina in the summer of 1999 throughout their annual moult (24 males, 18 females) and in the winter of 2000 throughout their midyear (or winter) haul-out (41 males, 39 females) (Table 1). These were the same individuals that were used in the study of diet, based on stomach contents (Field et al. 2007), and were aged 1 to 3 yr. All seals were caught by placing canvas bags over their heads (McMahon et al. 2000) and physically restrained until prescribed doses of a 1:1 mixture of tiletamine and zolazepam (Telazol, Forte Dodge) were administered intravenously (Field et al. 2002). A small area on the posterior dorsal surface was swabbed and shaved, and a $1 \mathrm{~cm}$ anterior-posterior incision was made into which a $6 \mathrm{~mm}$ biopsy corer was inserted, sampling the whole blubber layer down to the muscle (Best et al. 2003). The blubber samples were transferred to a solvent mixture of $2: 1 \mathrm{v} / \mathrm{v}$ chloroform and methanol with $0.05 \%$ by weight of the antioxidant agent butylated hydroxy toluene (BHT) and were stored at $-20^{\circ} \mathrm{C}$ until analysis. Blubber sampled from 52 adult female seals of known age (6 yr old) caught during the winter of 1999 and summer of 2000 (Bradshaw et al. 2003) were also included in the present study. Mean FA profiles of

Table 1. Mirounga leonina. Numbers of juvenile southern elephant seals sampled for fatty acid analysis in each age class $(1,2$ and $3 \mathrm{yr}$ olds) and sex class (female, male), as well as in the season/haul-out (summer, winter) in which each seal was sampled

\begin{tabular}{|lcrrrrrr|}
\hline Sex & \multicolumn{3}{c}{ Female } & & Male & Total \\
\hline Age (yr) & 1 & 2 & 3 & 1 & 2 & 3 & \\
Summer 1999 (moult) & - & 5 & 13 & 1 & 12 & 11 & 42 \\
Winter 2000 (haul-out) & 20 & 16 & 3 & 22 & 12 & 7 & 80 \\
Total & 20 & 21 & 16 & 23 & 24 & 18 & 122 \\
\hline
\end{tabular}

51 potential prey species of southern elephant seals were used from a FA profile library (Tables S1 to S6; available in MEPS Supplementary Material at www. int-res.com/articles/suppl/m384p303_app.pdf).

Lipid extraction. Blubber lipids were quantitatively extracted using a modified overnight (Bligh \& Dyer 1959), 1-phase methanol/chloroform/water extraction $(2: 1: 0.8, \mathrm{v} / \mathrm{v} / \mathrm{v})$. Following extraction, chloroform and water $(0.9 \% \mathrm{NaCl})$ were added to make a biphasic system (final solvent ratio, 1:1:0.9, v/v/v, methanol/chloroform/water). Total lipid was concentrated from the lower chloroform phase by rotary evaporation at $40^{\circ} \mathrm{C}$. A sub-sample of lipid was trans-methylated to produce fatty acid methyl esters (FAME) using a methanol/ chloroform/hydrochloric acid reagent (10:1:1, v/v/v; $80^{\circ} \mathrm{C} ; 2 \mathrm{~h}$ ). After the addition of water, FAMEs were extracted into hexane/dichloromethane $(4: 1, \mathrm{v} / \mathrm{v}, 3 \times$ $1.5 \mathrm{ml})$.

Gas chromatography. Gas chromatographic (GC) analyses were preformed using an Agilent 6890N GC (Avondale) equipped with an Equity-1 fused silica capillary column $(15 \mathrm{~m} \times 0.1 \mathrm{~mm}$ i.d., $0.1 \mu \mathrm{m}$ film thickness), a flame ionisation detector, a split/splitless injector and an Agilent Technologies 7683 Series autosampler and injector. Helium was the carrier gas. Samples were injected in splitless mode at an oven temperature of $120^{\circ} \mathrm{C}$. After injection, the oven temperature was

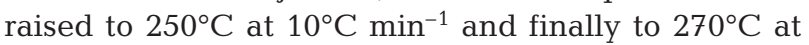
$3^{\circ} \mathrm{C} \mathrm{min}^{-1}$. Peaks were quantified with Agilent Technologies ChemStation software. Individual FAMEs were identified by mass spectral data and by comparing retention time data with those obtained for authentic and laboratory standards. GC results are typically subject to an error of $\pm 5 \%$ of the individual component area. GC-mass spectrometric (GC-MS) analyses were performed on representative samples on a Finnigan Thermoquest GCQ spectrometer fitted with an oncolumn injector with Thermoquest Xcalibur software. The GC was fitted with a capillary column similar to that described above.

Statistical analyses. We used a multivariate statistical approach to examine the differences in FA profiles between the different age, sex and season classes of the seals. We examined how these factors compared to potential prey species, and performed a single principal components analysis (PCA) on the FA profiles from seal blubber and from 51 prey species (including 36 fish species and 15 squid species) using a prey FA library from CSIRO and collaborators. We used the PCA scores for the first 2 components for each sample as the dependent variables when testing for the effects of age, sex and season. Each PC was therefore a single variable that contained information about the relative importance of each FA 
for each of the samples. These vectors are orthogonal to each other, ensuring they can be treated as independent variables. For these analyses, we restricted the 28 FAs identified in greater than trace amounts to 21 that were common to all age classes of seals and prey, to maintain consistency among variables. All FA values ( $\%$ of total FAs) were arcsine-square-root transformed prior to analysis, to maintain homoscedasticity.

A series of general linear models (GLM) were used to examine the importance of several individual and temporal attributes for explaining variation in the dietary data summarised by the principal components. We used season (factor), age (integer) and sex (factor). The response variable, either PCA Score 1 (PC1) or 2 (PC2), was modelled with combinations of the 3 terms (season, sex and age). PCA scores were also used to identify variations in blubber samples between juveniles and adult females. Model comparison was based on Akaike's information criterion corrected for small samples $\left(\mathrm{AIC}_{\mathrm{C}}\right.$ Burnham \& Anderson 2002). The information-theoretic weight of evidence $\left(W+_{i}\right)$ for each predictor was calculated by summing the model $\mathrm{AIC}_{\mathrm{c}}$ weights $\left(w_{i}\right)$ over all models in which each term appeared. Specific model comparisons were based on the information-theoretic evidence ratio (ER), which is equivalent to the $\mathrm{AIC}_{\mathrm{c}}$ weight $(w)$ of the full model divided by the $w$ of the null model. Higher ER values indicate higher likelihoods of the tested model relative to the null model. All statistical analyses were done using PRIMER (Version 5.2.9) and the R package (Version 2.6.0).

\section{RESULTS}

\section{Relationship of FA profiles between elephant seals and prey}

A total of 47 FAs were identified, of these 21 of the 28 FAs found in greater than trace amounts $(>0.5 \%)$ in the blubber of the juvenile seals were subsequently used for the PCA (Table 2), because these FAs were common between all juveniles, adult females and prey species. Raw data for the 28 FAs found in the blubber of juvenile southern elephant seals Mirounga leonina are provided as electronic supplementary materials (Tables $\mathrm{S} 7$ to S17; available at www.int-res.com/articles/ suppl/m384p303_app.pdf).

The first 2 principal components in the analyses that included all juvenile and adult seals, as well as the prey species, accounted for $65.2 \%$ of the total FA signature variation (Table 3). When PC1 was used, the

Table 2. Mirounga leonina. Averages $( \pm \mathrm{SD})$ for 21 fatty acids (\%) used in the principal components analysis out of a total of 28 fatty acids found in greater than trace amounts in juvenile southern elephant seal blubber sampled from different age classes, sexes and seasons. SFA: saturated fatty acids; SC-MUFA: short-chained monounsaturated fatty acids; LC-MUFA: long-chained monounsaturated; PUFA: polyunsaturated fatty acids

\begin{tabular}{|c|c|c|c|c|c|c|c|}
\hline Fatty acid & 1 yr old & 2 yr old & 3 yr old & Male & Female & Summer & Winter \\
\hline \multicolumn{8}{|l|}{ SFA } \\
\hline $14: 0$ & $2.84 \pm 0.8$ & $2.75 \pm 1.0$ & $2.72 \pm 1.2$ & $2.80 \pm 1.1$ & $2.74 \pm 0.9$ & $2.39 \pm 0.8$ & $2.94 \pm 1.0$ \\
\hline $16: 0$ & $12.40 \pm 0.8$ & $11.52 \pm 1.0$ & $11.45 \pm 1.0$ & $11.92 \pm 1.0$ & $11.69 \pm 1.2$ & $10.96 \pm 1.0$ & $12.13 \pm 1.0$ \\
\hline $17: 0$ & $0.27 \pm 0.1$ & $0.26 \pm 0.1$ & $0.29 \pm 0.1$ & $0.28 \pm 0.1$ & $0.26 \pm 0.1$ & $0.28 \pm 0.1$ & $0.26 \pm 0.1$ \\
\hline 18:0 & $2.96 \pm 0.4$ & $3.04 \pm 0.3$ & $3.09 \pm 0.6$ & $3.09 \pm 0.5$ & $2.95 \pm 0.3$ & $3.11 \pm 0.4$ & $2.94 \pm 0.4$ \\
\hline \multicolumn{8}{|l|}{ SC-MUFA } \\
\hline $16: 1 \omega 7$ & $7.71 \pm 1.0$ & $7.52 \pm 1.2$ & $7.82 \pm 1.6$ & $7.76 \pm 1.4$ & $7.57 \pm 1.2$ & $7.04 \pm 1.1$ & $7.91 \pm 1.3$ \\
\hline $18: 1 \omega 9$ & $30.11 \pm 2.3$ & $31.36 \pm 1.9$ & $33.03 \pm 2.9$ & $31.61 \pm 3.0$ & $31.13 \pm 2.0$ & $31.87 \pm 2.8$ & $30.73 \pm 2.2$ \\
\hline $18: 1 \omega 7$ & $7.12 \pm 0.8$ & $7.48 \pm 0.6$ & $7.78 \pm 1.0$ & $7.38 \pm 0.8$ & $7.50 \pm 0.8$ & $7.37 \pm 0.7$ & $7.37 \pm 0.9$ \\
\hline $18: 1 \omega 5$ & $0.64 \pm 0.1$ & $0.60 \pm 0.1$ & $0.55 \pm 0.1$ & $0.61 \pm 0.1$ & $0.60 \pm 0.1$ & $0.57 \pm 0.1$ & $0.61 \pm 0.1$ \\
\hline \multicolumn{8}{|l|}{ LC-MUFA } \\
\hline $20: 1 \omega 9+11$ & $9.99 \pm 1.4$ & $11.21 \pm 2.6$ & $10.55 \pm 3.0$ & $10.00 \pm 2.3$ & $11.28 \pm 2.4$ & $11.43 \pm 2.6$ & $10.01 \pm 2.1$ \\
\hline $20: 1 \omega 7$ & $0.62 \pm 0.1$ & $0.64 \pm 0.1$ & $0.65 \pm 0.1$ & $0.63 \pm 0.1$ & $0.63 \pm 0.1$ & $0.65 \pm 0.1$ & $0.62 \pm 0.1$ \\
\hline $22: 1 \omega 11+13$ & $2.18 \pm 0.5$ & $2.16 \pm 0.5$ & $1.87 \pm 0.6$ & $1.97 \pm 0.6$ & $2.21 \pm 0.4$ & $2.06 \pm 0.5$ & $2.07 \pm 0.5$ \\
\hline $22: 1 \omega 9$ & $1.10 \pm 0.2$ & $1.08 \pm 0.2$ & $1.03 \pm 0.2$ & $1.06 \pm 0.2$ & $1.09 \pm 0.2$ & $1.07 \pm 0.2$ & $1.06 \pm 0.2$ \\
\hline $22: 1 \omega 7$ & $0.15 \pm 0.1$ & $0.15 \pm 0.1$ & $0.17 \pm 0.1$ & $0.16 \pm 0.1$ & $0.16 \pm 0.1$ & $0.17 \pm 0.1$ & $0.15 \pm 0.1$ \\
\hline $24: 1 \omega 11+13$ & $0.30 \pm 0.1$ & $0.28 \pm 0.2$ & $0.23 \pm 0.2$ & $0.24 \pm 0.2$ & $0.31 \pm 0.1$ & $0.28 \pm 0.1$ & $0.27 \pm 0.2$ \\
\hline \multicolumn{8}{|l|}{ PUFA } \\
\hline $18: 4 \omega 3$ & $0.89 \pm 0.3$ & $0.69 \pm 0.2$ & $0.58 \pm 0.2$ & $0.76 \pm 0.3$ & $0.69 \pm 0.3$ & $0.53 \pm 0.2$ & $0.83 \pm 0.2$ \\
\hline $18: 2 \omega 6$ & $1.57 \pm 0.2$ & $1.62 \pm 0.2$ & $1.70 \pm 0.3$ & $1.62 \pm 0.2$ & $1.63 \pm 0.2$ & $1.58 \pm 0.2$ & $1.63 \pm 0.2$ \\
\hline $20: 4 \omega 6$ & $0.46 \pm 0.1$ & $0.47 \pm 0.1$ & $0.50 \pm 0.2$ & $0.48 \pm 0.2$ & $0.48 \pm 0.1$ & $0.49 \pm 0.1$ & $0.46 \pm 0.2$ \\
\hline $20: 5 \omega 3$ & $6.09 \pm 1.2$ & $5.29 \pm 1.2$ & $4.56 \pm 1.1$ & $5.43 \pm 1.4$ & $5.30 \pm 1.2$ & $4.29 \pm 0.9$ & $5.88 \pm 1.2$ \\
\hline $20: 4 \omega 3$ & $0.63 \pm 0.1$ & $0.63 \pm 0.1$ & $0.58 \pm 0.1$ & $0.62 \pm 0.1$ & $0.61 \pm 0.1$ & $0.57 \pm 0.1$ & $0.63 \pm 0.1$ \\
\hline $22: 6 \omega 3$ & $6.73 \pm 0.8$ & $6.13 \pm 1.0$ & $5.61 \pm 1.1$ & $6.32 \pm 1.1$ & $6.05 \pm 1.1$ & $5.68 \pm 1.0$ & $6.39 \pm 1.0$ \\
\hline $22: 5 \omega 3$ & $1.76 \pm 0.2$ & $1.74 \pm 0.2$ & $1.68 \pm 0.2$ & $1.78 \pm 0.2$ & $1.67 \pm 0.2$ & $1.70 \pm 0.2$ & $1.72 \pm 0.2$ \\
\hline
\end{tabular}


individual samples fell along a gradient ranging from samples enhanced in polyunsaturated fatty acids

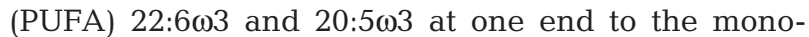

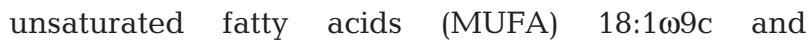
20:1 $\omega 9+\omega 11$ at the other extreme (Table 3, Fig. 1). For $\mathrm{PC} 2$, the samples ranged along a continuum from

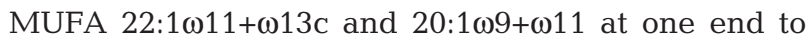
those dominated by the MUFA 16:1 107 and the saturated fatty acid (SFA) 14:0 at the other.

PC1 did not clearly separate the 2 prey groups, with squid and fish having similar mean scores (Fig. 1), indicating that PC1 cannot be used to distinguish dietary preferences for squid or fish between seals. However, PC1 did clearly distinguish prey from seal blubber with prey profiles having relatively more $22: 6 \omega 3$ and 20:5 $\omega 3$ than the seals, which had rela-

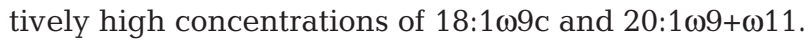
There was also a general increase in $18: 1 \omega 9 \mathrm{c}$ and $20: 1 \omega 9+\omega 11$ in seal blubber with age. We therefore interpreted this vector as containing information about the FA profiles unique to each taxon (seals vs. prey). Fish also exhibited considerable spread along this component.

Table 3. Principal component (PC) loadings for each of the 21 fatty acids - SFA: saturated fatty acids; SC-MUFA: shortchained monounsaturated fatty acids; LC-MUFA: longchained monounsaturated; PUFA: polyunsaturated fatty acids. Included in the analysis were fatty acids from 36 fish, 15 squid, 122 juvenile and 52 adult southern elephant seals. Only loadings less than 0.1 and greater than -0.1 are shown. Also indicated are the cumulative percent variations explained by PC1 and PC2

\begin{tabular}{|lcrr|}
\hline Fatty acid group & Fatty acid & PC1 & \multicolumn{1}{c|}{ PC2 } \\
\hline SFA & $17: 00$ & & \\
SFA & $14: 00$ & & -0.3494 \\
SFA & $18: 00$ & & 0.1229 \\
SFA & $16: 00$ & -0.2857 & -0.1240 \\
SC-MUFA & $18: 1 \omega 9 \mathrm{c}$ & 0.5564 & -0.2591 \\
SC-MUFA & $16: 1 \omega 7 \mathrm{C}$ & 0.1337 & -0.3954 \\
SC-MUFA & $18: 1 \omega 7 \mathrm{C}$ & 0.1291 & -0.1376 \\
SC-MUFA & $18: 1 \omega 5 \mathrm{c}$ & & \\
LC-MUFA & $20: 1 \omega 9+11$ & 0.3107 & 0.5262 \\
LC-MUFA & $22: 1 \omega 11+13 \mathrm{C}$ & 0.1894 & 0.3121 \\
LC-MUFA & $22: 1 \omega 9 \mathrm{c}$ & & 0.2335 \\
LC-MUFA & $20: 1 \omega 7$ & & \\
LC-MUFA & $22: 1 \omega 7 \mathrm{C}$ & & 0.1335 \\
LC-MUFA & $24: 1 \omega 11+13+9$ & & 0.2018 \\
PUFA & $22: 5 \omega 3$ & & \\
PUFA & $18: 2 \omega 6$ & & \\
PUFA & $20: 4 \omega 3$ & & \\
PUFA & $18: 4 \omega 3$ & & -0.1822 \\
PUFA & $20: 4 \omega 6$ & & 0.1267 \\
PUFA & $20: 5 \omega 3$ & -0.3897 & -0.1153 \\
PUFA & $22: 6 \omega 3$ & -0.5115 & 0.2024 \\
Cumulative & & & \\
percent variation $(\%)$ & & 65.2 \\
\hline
\end{tabular}

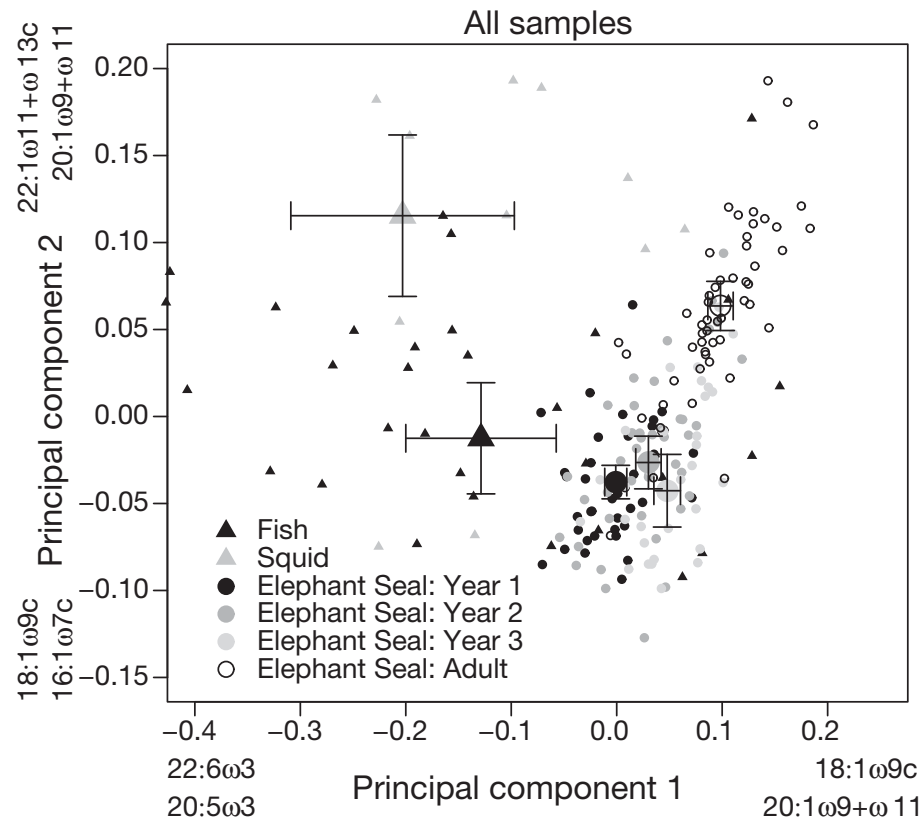

Fig. 1. Plot of the first 2 principal components (accounting for 49.8 and $16.4 \%$ of the total variance, respectively) for the analysis including 51 prey species and 174 elephant seal (Mirounga leonina; 122 juveniles and 52 adult females; Bradshaw et al. 2003) blubber samples. The 4 most influential fatty acids are indicated on each axis. The large symbols represent the means $\pm 95 \%$ confidence intervals for each of the PCA scores for each prey group and each age class of elephant seals

PC2 clearly separated squid from fish, but did not distinguish seals from prey, although adult seals were generally separated from juveniles along this axis (Fig. 1). The squid and adult seals had profiles with relatively high concentrations of the LC (longchain)-MUFA (LC denotes $\geq \mathrm{C}_{20}$ ) 20:1 $\omega 9+\omega 11$ and $22: 1 \omega 11+\omega 13 \mathrm{c}$, while fish and juvenile seals had higher concentrations of the SC (short-chain)-MUFA

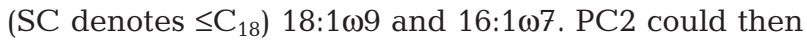
be regarded as containing dietary information on seals based on similarity to the FA profiles of squid and fish.

\section{Effects of sex, age and season}

Of the GLM relating the individual PC1 scores for juvenile seals (i.e. the non-dietary component), age + sex + season was the top-ranked model (Table 4), with an AAIC $_{\mathrm{c}}$ of 0.657 , with the ER showing that it fitted the data almost 2.3 times better than the next model (age + season). The age + sex + season model explained $31.5 \%$ of the deviance in PC1 (\%DE). This indicates that among the juvenile seals, there were differences in the FA profiles for each of the covariates. When the adult female data were included 
Table 4. Mirounga leonina. Model selection results of the generalised linear model for juvenile seal data only and for both juvenile and adult data (Bradshaw et al. 2003). The models relate the principal component scores (PC1 and PC2) to each individual's sex and age and to the season (summer or winter) in which the blubber sample was collected. The models are ranked in the order of Akaike weights $\left(w A \mathrm{IC}_{\mathrm{c}}\right) \cdot \log (L)$ : maximized log-likelihood of the model; $K$ : number of estimated parameters; $\mathrm{AIC}_{c}$ : selection criteria; $\Delta \mathrm{AIC}_{\mathrm{c}}$ : difference between the model's $\mathrm{AIC}_{\mathrm{c}}$ value and the minimum $\mathrm{AIC}_{\mathrm{c}}$ value; \%DE: percent deviance explained by model

\begin{tabular}{|c|c|c|c|c|c|c|}
\hline Model & $K$ & $\log L$ & $\mathrm{AIC}_{\mathrm{c}}$ & $\Delta \mathrm{AIC}_{\mathrm{c}}$ & $w \mathrm{AIC}_{\mathrm{c}}$ & $\% \mathrm{DE}$ \\
\hline \multicolumn{7}{|l|}{ PC1: juveniles only } \\
\hline PC1 age + sex + season & 6 & 235.52 & -458.29 & 0.00 & 0.66 & 31.51 \\
\hline PC1 age + season & 5 & 233.58 & -456.64 & 1.65 & 0.29 & 29.28 \\
\hline PC1 sex + season & 4 & 229.76 & -451.17 & 7.12 & 0.02 & 24.67 \\
\hline $\mathrm{PC} 1 \sim$ age + sex & 5 & 230.78 & -451.04 & 7.25 & 0.02 & 25.93 \\
\hline PC1 age & 4 & 229.27 & -450.20 & 8.09 & 0.01 & 24.06 \\
\hline PC1 season & 3 & 227.84 & -449.48 & 8.82 & 0.01 & 22.24 \\
\hline PC1 sex & 3 & 213.71 & -421.22 & 37.07 & 0.00 & 1.79 \\
\hline $\mathrm{PC} 1 \sim 1$ & 2 & 212.62 & -421.14 & 37.16 & 0.00 & 0.00 \\
\hline \multicolumn{7}{|l|}{ PC1: juveniles and adults } \\
\hline PC1 age + sex + season & 7 & 328.84 & -642.99 & 0.00 & 0.67 & 55.59 \\
\hline PC1 age + season & 6 & 327.02 & -641.54 & 1.45 & 0.33 & 54.65 \\
\hline PC1 age + sex & 6 & 319.60 & -626.69 & 16.30 & 0.00 & 50.58 \\
\hline PC1 age & 5 & 318.25 & -626.15 & 16.85 & 0.00 & 49.81 \\
\hline PC1 sex + season & 4 & 292.41 & -576.59 & 66.40 & 0.00 & 32.33 \\
\hline PC1 season & 3 & 275.93 & -545.71 & 97.28 & 0.00 & 18.13 \\
\hline PC1 sex & 3 & 273.02 & -539.91 & 103.09 & 0.00 & 15.33 \\
\hline $\mathrm{PC} 1 \sim 1$ & 2 & 258.63 & -513.18 & 129.81 & 0.00 & 0.00 \\
\hline \multicolumn{7}{|l|}{ PC2: juveniles only } \\
\hline PC2 age + sex + season & 6 & 209.14 & -405.54 & 0.00 & 0.87 & 21.10 \\
\hline PC2 age + season & 5 & 205.93 & -401.33 & 4.21 & 0.11 & 16.80 \\
\hline PC2 sex + season & 4 & 202.98 & -397.62 & 7.92 & 0.02 & 12.65 \\
\hline PC2 season & 3 & 200.28 & -394.36 & 11.18 & 0.00 & 8.67 \\
\hline PC2 sex & 3 & 196.93 & -387.65 & 17.89 & 0.00 & 3.45 \\
\hline PC2 age + sex & 5 & 198.18 & -385.85 & 19.69 & 0.00 & 5.44 \\
\hline $\mathrm{PC} 2 \sim 1$ & 2 & 194.80 & -385.50 & 20.04 & 0.00 & 0.00 \\
\hline $\mathrm{PC} 2 \sim$ age & 4 & 196.00 & -383.65 & 21.89 & 0.00 & 1.96 \\
\hline \multicolumn{7}{|l|}{ PC2: juveniles and adults } \\
\hline PC2 age + sex + season & 7 & 293.13 & -571.58 & 0.00 & 0.87 & 55.45 \\
\hline PC2 age + season & 6 & 290.18 & -567.85 & 3.73 & 0.13 & 53.91 \\
\hline $\mathrm{PC} 2 \sim$ age + sex & 6 & 279.53 & -546.56 & 25.02 & 0.00 & 47.87 \\
\hline $\mathrm{PC} 2 \sim$ age & 5 & 277.43 & -544.50 & 27.08 & 0.00 & 46.59 \\
\hline PC2 sex + season & 4 & 251.93 & -495.62 & 75.95 & 0.00 & 28.28 \\
\hline PC2 sex & 3 & 241.59 & -477.03 & 94.55 & 0.00 & 19.17 \\
\hline PC2 season & 3 & 232.34 & -458.53 & 113.05 & 0.00 & 10.05 \\
\hline $\mathrm{PC} 2 \sim 1$ & 2 & 223.18 & -442.29 & 129.29 & 0.00 & 0.00 \\
\hline
\end{tabular}

in the analysis, age + sex + season was again the topranked model (Table 4 ), with an increase in \%DE to $55.6 \%$.

There were several apparent trends in the PC1 data (Fig. 2a). Within an age class (with the exception of $2 \mathrm{yr}$ old females), the PC scores tended to be lower (i.e. the FA profiles contained higher concentrations of 22:6 63 and 20:5 $\omega 3$ in winter than in summer. There was little difference between males and females in any age or season class, with the exception of $3 \mathrm{yr}$ olds in winter, in which cases females had relatively more $18: 1 \omega 9 \mathrm{c}$ and 20:1 $\omega 9+\omega 11$. Support for the age effect in the final model may have arisen because the adult age class was only present for females. The most striking effect was age, particularly for females for which the data spanned the greatest range of ages. In that case, the average PC1 scores increased steadily (becoming

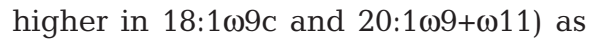
the females increased in age.

Of the GLM relating the individual PC2 scores from juveniles, age + sex + season was again the top-ranked model (Table 4), with a WAIC $_{\mathrm{c}}$ of 0.657 , fitting the data (ER) 2.3 times better than the next model. The age + sex + season model had a \%DE of $21.1 \%$. When the adult female data were included in the analysis, age + sex + season was again the top-ranked model (Table 4), accounting for $55.5 \%$ of the deviance. As with PC1, there were consistent differences between the seasons, with summer values being on average higher (i.e. more squidlike) than winter values for each age class (Fig. 2b). Seasonal differences were relatively minor compared to the full range of PC2 scores (Fig. 1) and therefore likely to represent relatively minor shifts in diet. The scores also varied little between age classes, and, in particular, the 1 to 3 yr old animals were similar, with the exception of $3 \mathrm{yr}$ old males that had more fish-like signatures. The most pronounced differences were between adult females and juveniles, with the adults having higher PC2 scores, on average, indicating more squid-like profiles, although inter-individual variation was high (Bradshaw et al. 2003).

\section{DISCUSSION}

The Southern Ocean is an unpredictable environment with highly seasonal availability of resources (Knox 1993, Pakhomov \& McQuaid 1996), and it is a region facing a number of management challenges due to increasing fishing activity and regional ocean warming (Weimerskirch et al. 2003, McMahon \& Burton 2005). The functional role of larger marine predators is currently poorly understood, especially in this highly dynamic environment, where future ecological disruptions due to climate change are expected (Wei- 
(a) PC1

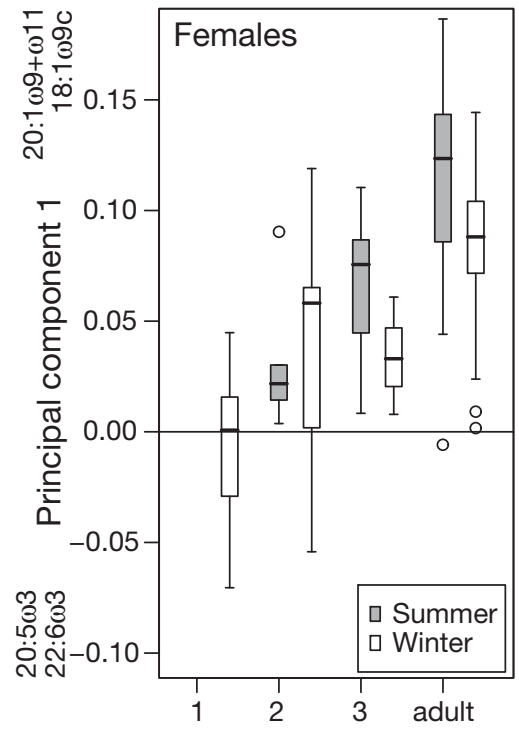

(b) PC2

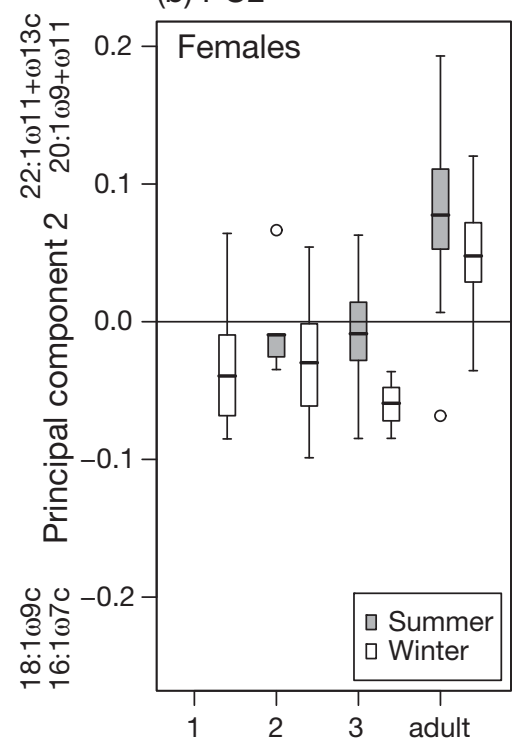

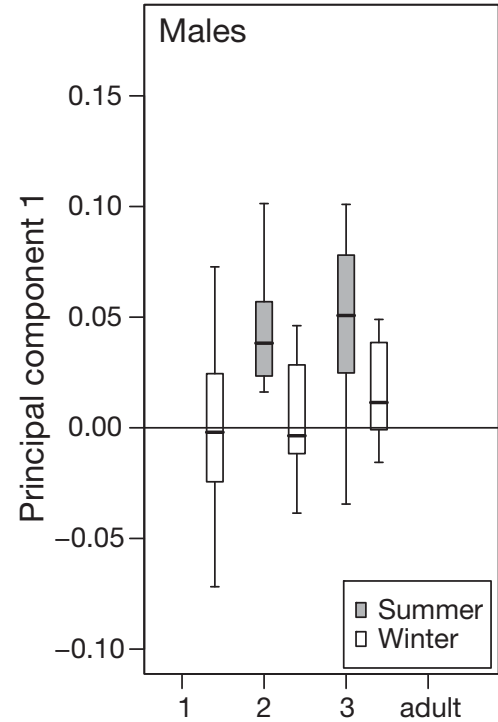

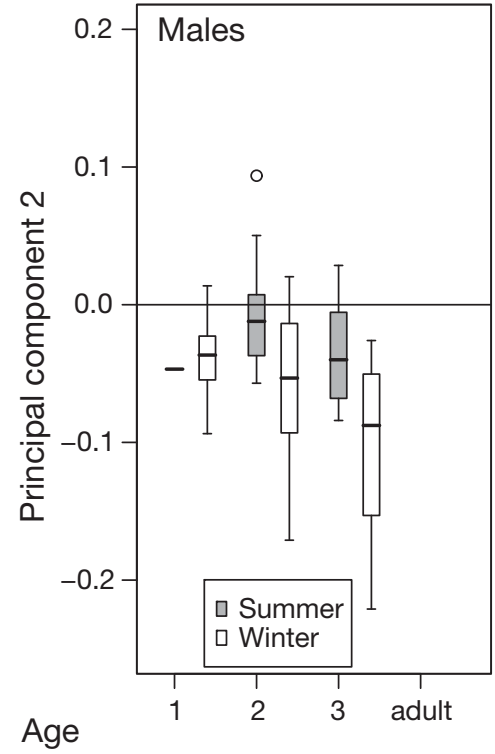

Age

graphic studies have indicated that juvenile survival is an important contributing factor in observed declines (Hindell 1991, Hindell et al. 1994, Laws 1994, McMahon et al. 2005), but this is difficult to understand unless there is some kind of intra-specific resource partitioning occurring and the younger seals are exploiting different resources than the older animals. Earlier studies have demonstrated that, while there is pronounced age-specific spatial and temporal separation in feeding areas (Field et al. 2005a), attempts to confirm this from dietary studies were less conclusive due to the limitations of stomach content analysis (Harvey \& Antonelis 1994, Fea \& Harcourt 1997).

\section{Physiological aspects associated with FA profiles}

A general increase in MUFA and decrease in PUFA with age was found among southern elephant seals. Specifically, PUFAs were lowest in adult females and highest in 1 yr olds, which stands to reason considering the PUFAs

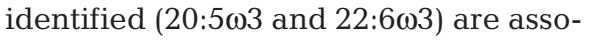
ciated with the phospholipids of biomembranes, hormone precursors and neurological function, which are important for growth and development and, thus, are more likely to be utilized by younger seals (Innis 2005). High concentrations of these PUFAs have also been identified in Weddell seal pups (Wheatley et al. 2007). In contrast, some MUFAs $(20: 1 \omega 9+\omega 11$ and 22:1 $\omega 11+\omega 13)$ increased with age. MUFAs offer optimal characteristics for energy storage by providing higher energy density than PUFAs, and higher mobilization and oxidation rates than SFAs (Maillet \& Weber 2006). A positive relationship

merskirch et al. 2003, McMahon \& Burton 2005). Our expectation then that a species living in such an unpredictable environment should demonstrate resource partitioning (Polis 1984, Bolnick et al. 2003, Field et al. 2005a) was generally upheld for southern elephant seals Mirounga leonina. Using FA signature analysis, we demonstrated clear dietary differences between age and sex classes, reinforcing the prediction of intraspecific resource partitioning in this species. Demo- between age, body mass, dive duration and time spent at sea has been identified in elephant seals (Hindell et al. 2000, Field et al. 2001, 2005a, McConnell et al. 2002). Thus, the observed increase in MUFA appears to indicate an increasing energy storage capacity, allowing adult seals to travel further, dive for longer and to greater depths to exploit different prey. In addition, higher levels of MUFA have arisen because the adult age class was only present for females who may 
be optimizing energy stores to prepare for the breeding effort.

We also found seasonal differences in some MUFAs and PUFAs, which is consistent with previous results for adult females only (Bradshaw et al. 2003). The summer or pre-moult period represents a time when the rate of mass gain (for both lean and fat tissues) in juvenile seals is almost double that observed in the winter prior to the mid-year haul-out (Field et al. 2005b). However, lean mass loss is greatest during the summer moult (Field et al. 2005b). Juveniles also spend less time at sea in the summer (Field et al. 2005a). The higher MUFA proportions may optimize energy storage, allowing juveniles to fast for longer periods during the summer moult. Gender-specific differences were also apparent in the seal FA profiles, but only in $3 \mathrm{yr}$ olds. Juvenile females use more lean tissue and less adipose tissue than males of similar size and age during the same season (Field et al. 2005b). Therefore, the observed increase in MUFA in females may be due to the energy-storage capacity of MUFA and early development of females towards sexual maturity. In addition, juvenile males have a greater daily expenditure rate and grow faster than females, so males may be metabolizing more MUFA than females at this age during the winter.

\section{Prey preference and dietary aspects associated with FA profiles}

Along the fish to squid prey gradient we identified, adult female elephant seals were also clearly separated from juveniles, suggesting that adult females were consuming different prey. Juveniles had lower concentrations of LC-MUFA and higher concentrations of SC-MUFA, and were thus more fish-like relative to adult females that were more squid-like. Prior to this analysis, elephant seals were generally regarded as being primarily squid feeders, albeit on very little empirical basis. Our results imply that juveniles exploit fish prey more readily, at least than adult females, and we suggest that their ability to hunt and capture squid improves as they age. Southern elephant seals exhibit age-specific spatial and temporal resource partitioning in foraging areas (Field et al. 2005a), and adult females have dietary differences between foraging areas (Bradshaw et al. 2003). As juveniles develop they are able to dive deeper and for longer periods, and they expand their range, potentially encountering more prey species (Le Boeuf et al. 1996, 2000, Slip 1997, Hindell et al. 2000, Irvine et al. 2000, Field et al. 2001, 2005a, McConnell et al. 2002). Differences in diet between juveniles and adult females suggest resource partitioning occurs in response to the large metabolic and physiological differences with age that limit juveniles. By consuming a different diet compared to adult females, juvenile southern elephant seals may effectively experience reduced intra-specific competition.

Ours is the first study to identify clear differences in diet between juvenile and adult female southern elephant seals. We have also contradicted the previous general consensus of squid-dominated diets for all age classes, showing that juvenile diets are composed more of fish prey than previously suspected. To exploit the unpredictable resources of the Southern Ocean and to maintain their large energy requirements, we suggest that southern elephant seals benefit from spatial and dietary resource partitioning. This dietary segregation of the population into juveniles and adult females may reduce intra-specific competition and increase the likelihood of successful individual foraging

Identifying this ecological separation is an important step in understanding the mechanisms underpinning the declines in elephant seal populations. At present the declines are thought to be ultimately driven by changes in the marine environment, and decreasing juvenile survival may be an important contributing factor. The results identified from our analysis suggest that reduced juvenile survival may be attributed to increased energetic demands of growth coupled with an inability to forage as efficiently as adults (smaller body size) on the same prey. These results support the idea that juvenile seals exploit different resources than adults, making it possible for them to be effected differently by changes in the distribution of prey due to climatic factors (Weimerskirch et al. 2003, McMahon \& Burton 2005). Although caution should be taken with the interpretation of dietary and non-dietary factors, FASA has the ability to provide information on the requirements for different stages in the life history of a species and on the long-term dietary habits. This approach, coupled with information on the spatial and temporal patterns of foraging behaviour, can then be used to assess the greater potential of dietary resource partitioning between different sub-groups of a population and, ultimately, the functional role of this predator in the Southern Ocean.

Acknowledgements. We thank the members of the 51st to 53rd Australian National Antarctic Research Expeditions (ANARE) for their assistance during field work, the Australian Antarctic Division for logistics support, especially J. van den Hoff, M. Biuw and C. McMahon, and K. Wheatley for help with laboratory work. Samples and data were collected with Australian Antarctic Animal Ethics Committee approval and Tasmanian Parks and Wildlife service permits. Funding was provided by the Antarctic Science Advisory Committee, the Sea World Research and Rescue Foundation and the Australian Research Council. 


\section{LITERATURE CITED}

Best NJ, Bradshaw CJA, Hindell MA, Nichols PD (2003) Vertical stratification of fatty acids in the blubber of southern elephant seals (Mirounga leonina): implications for diet analysis. Comp Biochem Physiol B 134:253-263

Bligh EG, Dyer WJ (1959) A rapid method of lipid extraction and purification. Can J Biochem Physiol 37:911-917

Bolnick DI, Svanback R, Fordyce JA, Yang LH (2003) The ecology of individuals: incidence and implications of individual specialization. Am Nat 161:1-28

Borobia M, Gearing PJ, Simard Y, Gearing JN, Beland P (1995) Blubber fatty acids of finback and humpback whales from the Gulf of St. Lawrence. Mar Biol 122: 341-353

> Bradshaw CJA, Hindell MA, Best NJ, Phillips KL, Wilson G, Nichols PD (2003) You are what you eat: describing the foraging ecology of southern elephant seals (Mirounga leonina) using blubber fatty acids. Proc R Soc Lond B Biol Sci 270:1283-1292

Bremer J, Norum KR (1982) Metabolism of very long-chained monounsaturated fatty acids (22:1) and the adaption to their presence in the diet. J Lipid Res 23:243-256

Brown DJ, Boyd IL, Cripps GC (1999) Fatty acid signature analysis from the milk of Antarctic fur seals and southern elephant seals from South Georgia: implications for diet determination. Mar Ecol Prog Ser 187:251-263

Burnham KP, Anderson DR (2002) Model selection and multimodel inference: a practical information-theoretical approach, 2nd edn. Springer-Verlag, New York

Fea N, Harcourt R (1997) Assessing the use of faecal and regurgitate analysis as a means of determining the diet of New Zealand fur seals. In: Mammal research in the Southern Hemisphere, Vol 1. Status, ecology and medicine. Surrey Beatty \& Sons, Chipping Norton, p 143-150

Field IC, Hindell MA, Slip DJ, Michael KJ (2001) Foraging strategies of southern elephant seals (Mirounga leonina) in relation to frontal zones and water masses. Antarct Sci 13:371-379

Field IC, McMahon CR, Burton HR, Bradshaw CJ, Harrington $\mathrm{J}$ (2002) Effects of age, size and condition of elephant seals (Mirounga leonina) on their intravenous anaesthesia with tiletamine and zolazepam. Vet Rec 151:235-240

Field IC, Bradshaw CJA, Burton HR, Sumner MD, Hindell MA (2005a) Resource partitioning through oceanic segregation of foraging juvenile southern elephant seals (Mirounga leonina). Oecologia 142:127-135

> Field IC, Bradshaw CJA, Burton HR, Sumner MD, Hindell MA (2005b) Juvenile southern elephant seals exhibit seasonal differences in energetic requirements and use of lipids and protein stores. Physiol Biochem Zool 78: 491-504

Field IC, Bradshaw CJA, van den Hoff J, Burton HR, Hindell MA (2007) Age-related shifts in the diet composition of southern elephant seals expand overall foraging niche. Mar Biol 150:1441-1452

> Green K, Burton HR (1993) Comparison of the stomach contents of southern elephant seals, Mirounga leonina, at Macquarie and Heard Islands. Mar Mamm Sci 9:10-22

Harvey JT, Antonelis GA (1994) Biases associated with nonlethal methods of determining the diet of northern elephant seals. Mar Mamm Sci 10:178-187

Herman DP, Burrows DG, Wade PR, Durban JW and others (2005) Feeding ecology of eastern North Pacific killer whales Orcinus orca from fatty acid, stable isotope and organochlorine analyses of blubber biopsies. Mar Ecol Prog Ser 302:275-291
Hindell M (1991) Some life-history parameters of a declining population of southern elephant seals (Mirounga leonine). J Anim Ecol 60:119-134

Hindell MA, Slip DJ, Burton HR (1994) Possible causes for the decline of southern elephant populations in the southern Pacific and southern Indian Oceans. In: Le Boeuf BJ, Laws RM (eds) Elephant seals: population ecology, behaviour and physiology. University of California Press, Berkeley, CA, p 66-84

Hindell MA, Lea M, Morrice M, McMahan CR (2000) Metabolic limits on dive duration and swimming speed in the southern elephant seal, Mirounga leonina. Physiol Biochem Zool 73:790-798

> Hindell MA, Bradshaw CJ, Sumner MD, Michael KJ, Burton HR (2003) Dispersal of female southern elephant seals and their prey consumption during the austral summer: relevance to management and oceanographic zones. J Appl Ecol 40:703-715

Hooker SK, Iverson SJ, Ostrom P, Smith SC (2001) Diet of northern bottlenose whales inferred from fatty acid and stable isotope analyses of biopsy samples. Can J Zool 79: 1442-1454

Innis SM (2005) Essential fatty acid metabolism during early development. In: Burrin DG, Mersmann HJ (eds) Biology of metabolism in growing animals. Elsevier Ltd, Sydney, p 235-274

> Irvine LG, Hindell MA, van den Hoff J, Burton HR (2000) The influence of body size on dive duration of under-yearling southern elephant seals (Mirounga leonina). J Zool 251: 463-471

Iverson SJ, Frost KJ, Lowry LF (1997) Fatty acid signatures reveal fine scale structure of foraging distribution of harbour seals and their prey in Prince William Sound Alaska. Mar Ecol Prog Ser 151:255-271

Iverson SJ, Field C, Bowen WD, Blanchard W (2004) Quantitative fatty acid signature analysis: a new method of estimating predator diets. Ecol Monogr 74:211-235

Knox G (1993) Biology of the Southern Ocean. University of Canterbury, Christchurch

Laws R (1994) History and present status of southern elephant seal population. In: Le Boeuf BJ, Laws RM (eds) Elephant seals: population ecology, behaviour and physiology. University of California Press, Berkeley, CA, p 49-65

Le Boeuf BJ, Morris PA, Blackwell SB, Crocker DE, Costa DP (1996) Diving behaviour of juvenile northern elephant seals. Can J Zool 74:1632-1644

> Le Boeuf BJ, Crocker DE, Costa DP, Blavkwell SB, Webb PM, Houser DS (2000) Foraging ecology of northern elephant seals. Ecol Monogr 70:353-382

Maillet D, Weber JM (2006) Preformance-enhancing role of dietary fatty acids in a long-distance migrant shore-bird: the semipalmated sandpiper. J Exp Biol 209:2686-2695

McConnell BJ, Fedak MA, Burton HR, Engelhard GH, Reijnders PJH (2002) Movements and foraging areas of naïve, recently weaned southern elephant seal pups. J Anim Ecol 71:65-78

McMahon CR, Burton HR (2005) Climate change and seal survival: evidence for environmentally mediated changes in elephant seal, Mirounga leonina, pup survival. Proc R Soc Lond B 272:923-928

> McMahon CR, Burton HR, Slip DJ, McLean S, Bester M (2000) Field immobilisation of southern elephant seals with intravenous tiletamine and zolazepam. Vet Rec 146:251-254

> McMahon CR, Burton HR, Bester MN (2003) A demographic comparison of two southern elephant seal populations. J Anim Ecol 72:61-74

McMahon CR, Bester MN, Burton HR, Hindell MA, Bradshaw 
CJA (2005) Population status, trends and a re-examination of the hypotheses explaining the recent declines of the southern elephant seal Mirounga leonina. Mammal Rev 35:82-100

Moller P, Born EW, Dietz R, Ruzzante D, Haug T, Oien N (2000) Differences in fatty acid composition of blubber of minke whales (Balaenoptera acutorostrata) from Greenland, NE Atlantic Ocean and the North Sea, 1998. International Whaling Commission, Cambridge

Nordstrom CA, Wilson LJ, Iverson SJ, Tollit DJ (2008) Evaluating quantitative fatty acid signature analysis (QFASA) using harbour seals Phoca vitulina richardsi in captive feeding studies. Mar Ecol Prog Ser 360:245-263

Olsen E, Grahl-Nielsen O (2003) Blubber fatty acids of minke whales: stratification, population identification and relation to diet. Mar Biol 142:13-24

Pakhomov EA, McQuaid CD (1996) Distribution of surface zooplankton and seabirds across the Southern Ocean. Polar Biol 16:271-286

Polis GA (1984) Age structure component of niche width and

Editorial responsibility: Michael Castellini,

Fairbanks, Alaska, USA intra-specific resource partitioning: Can age groups function as ecological species? Am Nat 123:541-564

Slip DJ (1995) The diet of southern elephant seals (Mirounga leonina) from Heard Island. Can J Zool 73:1519-1528

Slip DJ (1997) Diving and foraging behaviour of juvenile southern elephant seals from Heard Island. In: Hindell M, Kemper C (eds) Marine mammal research in the Southern Hemisphere, Vol 1. Status, ecology and medicine. Surrey Beatty \& Sons, Chipping Norton, p 114-124

Volpe JJ, Vagelos PR (1973) Saturated fatty acid biosynthesis and its regulation. Annu Rev Biochem 42:21-60

Wakil SJ, Stoops JK, Joshi VC (1983) Fatty acid synthesis and its regulation. Annu Rev Biochem 52:537-579

Weimerskirch H, Inchausti P, Guinet C, Barbraud C (2003) Trends in bird and seal populations as indicators of a system shift in the Southern Ocean. Antarct Sci 15:249-256

Wheatley KE, Nichols PD, Hindell MA, Harcourt RG, Bradshaw CJA (2007) Temporal variation in the vertical stratification of blubber fatty acids alters diet predictions for lactating Weddell seals. J Exp Mar Biol Ecol 352: 103-113

Submitted: October 28, 2008; Accepted: March 12, 2009

Proofs received from author(s): May 14, 2009 